\title{
Pentsamendu estatistikoa: ulermena eta ohiko akatsak
}

\author{
Ainhoa Berciano, Guadalupe Gutiérrez, Jon Anasagasti \\ Matematikaren eta Zientzia Esperimentalen Didaktika Saila. \\ Bilboko Irakasleen Unibertsitate Eskola. \\ Euskal Herriko Unibertsitatea (UPV/EHU)
}

Laburpena: Egungo gizartean, hezkuntza estatistikoa oso garrantzitsua da. Artikulu honek hainbat hausnarketa egingo ditu estatistika ikas-irakaskuntza errealitatearekin lotzeko beharraz. Horretarako, irakasle-eskola ikasleek dituzten kognizio-akats azterketa hartuko du abiapuntu. Izan ere, elkarrengandik urrun daude, eskolan ikasten den eta bizitzan erabiltzen denaren artean; horrela, Estatistikako kontzeptuak era algoritmikoan ikasten dira eta ondorioz lortutako ezagutzak ez dira esanguratsuak. Azkenik, behartuta egongo gara estatistika eguneroko arazoekin uztartzeko, hezkuntzaren metodologi aldaketaren proposamena egitera.

\begin{abstract}
Nowadays, in our society statistics knowledge is really important. The purpose of this paper is to reflect about the need to join teaching-learning of statistics with real life. To justify this fact, we will analyze the standard errors done by our students of the Teacher Training Faculty, and we will show how far has been the academic life of our students to the real life, where until now, statistical concepts has been studied algorithmically, producing a non comprehensive understanding. Finally, we will be obliged to propose an alternative way to study statistics, where a methodological change will be required on the education consisting on the problem based learning methodology.
\end{abstract}

\section{SARRERA}

2010.eko urriaren 20an Nazio Batuak erakundeak (NB) Estatistikaren Nazioarteko lehenengo eguna ospatu zuen. Bere ospakizunerako, Ban KiMoonenek, NBen idazkari orokorrak, hurrengo ohar ofiziala idatzi zuen [1]:

«Statistics permeate modern life. They are the basis for many governmental, business and community decisions. They provide information and insight about the trends and forces that affect our lives. [...] 
Statistics are a vital tool for economic and social development, including our efforts to achieve the Millennium Development Goals. For development to succeed, we need data collection and statistical analysis of poverty levels, access to education and the incidence of disease [...]».

Informazio eta komunikazioaren gizartean, gure inguruan gertatzen diren egoerak adierazteko ezinbestekoak dira Estatistikako kontzeptuak, egunkarietan, ikerketa-artikuluetan eta hainbat txostenetan agertzen baitzaizkigu. Datu multzo batek duen informazioaz jabetzeko, estatistikak hainbat tresna eskaintzen dizkigu. Baina jakin beharra dago datuak ondo irakurtzeko eta aztertzeko tresneria egokia zein den eta nola erabil dezakegun ere. Bestalde, askotan estatistikaz baliatu behar gara gure adierazpen propioak egiaztatzeko ere. Hezkuntzak aurre egin behar die bi ikuspuntu hauei: gizakiok ondo ikasi behar dugu emaitza estatistikoak irakurtzen, eta interpretazio zehatzak ematen; bide batez, gai izan behar dugu datu multzo batetik informazio garrantzitsuena lortzeko.

Hori dela eta, azken urte hauetan estatistika-ezagupenak gero eta garrantzi handiagoa hartu du. UNESCOk eta OECDek behin eta berriro adierazi dute gizaki guztiek ezagupen estatistikoa izan behar dutela beraien ingurua uler dezaten.

\section{BAINA, ZER DA ESTATISTIKA-EZAGUPENA?}

Hasieran Estatuaren informazio multzoa baino ez zen, eta hortik dator izena. Baina une honetan Gizarte Zientzietan eta Zientzia Ikerketen lorpen prozesu metodo izatera iritsi da. Estatistika izena ematen diogu datu multzo bat aztertzeko eta datuak era laburrago eta esanguratsuago batean aurkezteko helburua duen teknika multzoari.

Askotan ospe txarra du. Izan ere, erabiltzaile azpijaleek iruzurrak egiten dizkigute, besteak beste populazio edo lagina kopuruaren datua ezkutatzen denean edo iragarpenetan balioa (positibo zein negatiboa) kutsatzen denean.

Kontzeptu mailan, bi arlo handi bereizi behar ditugu, hain zuzen ere estatistika deskribatzailea eta estatistika inferentziala. Estatistika deskribatzaileak helburu gisa hartzen du elementu multzo bati dagozkion datuak biltzea, eratzea, laburtzea eta deskribatzea. Bestalde, estatistika inferentziala dugu lagin batean lortutako emaitzak populazio osora orokortzea helburu duena. Bien arteko desberdintasuna nabaria izanik ere, osagarriak dira eta bien ezagupena ezinbestekoa da edozein gizakirentzat.

OCDEk dioenez, alfabetatze matematikoa da banakako gaitasuna non gure inguruan matematikaren zeregina uler eta identifika daitekeen eta iri- 
tziak ondo bideratzeko matematikak erabil daitezkeen gizaki eraikitzaile, konprometitu eta islatzaile bezala [2].

Alfabetatze hau neurtzeko, OCDEk PISA proba diagnostikoa definitu zuen, matematikaren edukiak lau zatitan banatuz: kopurua, espazioa eta forma, aldaketa eta erlazioak, eta zalantza, non zalantza blokean datuak eta zoriaren tratamendua aztertzen diren.

Datuen analisian oinarritzen dira estatistika eta probabilitatearen edukiak eskola-curriculumean. Ondorioz, estatistika-tresna berezien multzotzat har daiteke eduki horiek. Datu multzoak, fenomeno aldakorrak eta zehaztugabeak jorratzeko era zentzuduna da estatistika-hezkuntzaren helburua [3]. PISA egitasmoa uste konbentzionaletatik erabat aldentzen da, ezagupen matematikoa eta ezagupen estatistikoa desberdinduz, eta estatistikak matematikari datu enpirikotik sortzen duen arrazonamendua gehitzen diola adieraziz [4].

\section{EGUNGO ESTATISTIKA-HEZKUNTZAREN EGOERA}

Curriculum ofizialak dioenez, estatistikaren kontzeptuak eta prozedurak maila guztietan lantzen dira, haur-hezkuntzatik unibertsitatera. Era batera zein bestera, formulak, grafikoen adierazpenak, zentralizazio eta sakabanatze neurriak kalkulatzen dira, eta gainera, guztiok erabiltzen ditugu eguneroko bizitzan kontzeptu estatistikoak.

Dena dela, gehienetan, ez gara estatistikaren erabileraz ohartzen eta batez bestekoa, portzentajea, eta abarreko hitzak behin eta berriro aipatu arren, ez diegu behar duten esanahia ematen. Bestalde, erabakiak hartzeko unean emaitza estatistikoak ontzat hartzen ditugu konfiantza tarte batez hartu beharrean.

Estatistika-hezkuntzak dituen eragozpenei dagokienez, besteak beste Shaughnessyk, Garfieldek eta Geerrek ikusi zuten ikasleek bai bigarren hezkuntzan bai unibertsitatean estatistika ikasi arren, haietako askok ez zekitela emaitza estatistikorik ondorioztatzen [5].

Arrazonamendu estatistikorako ahalmena sortzeko asmoz, irakasle askok kontzeptu eta prozedurak irakasten dituzte, ikasleei datu multzo eta estatistika programak erabiltzeko aukerak emanez [6]. Zoritxarrez, ikasgelan proposatzen diren jarduerak urrunegi kokatzen dira ikasleen testuinguruetatik, eta haiek ez dituzte egokiro garatzen estatistikaren kontzeptuak [7].

Errealitateari begira, esan dezakegu eskolan oso irakasle gutxik irakasten dutela estatistika, eta haietako gehienek modu abstraktuan egiten dutela, hau da, kontzeptu estatistikoen formulen kalkulu soila irakasten dute [8]. Berriro ere, gehiago erreparatzen zaio kalkulu algoritmikoari, bere esanahia aztertu barik, eta logikaren eta interpretazioaren ikuspegiak baztertuz. Ho- 
nen ondorioz, ikasleriaren portzentaje handiak badaki batez bestekoa kalkulatzen, baina ez du ulertzen bere esanahia, hau da, emandako formula modu automatikoan aplikatzen du. Gainera, kasu askotan ez du emandako arazoa ateratako emaitza matematikoekin uztartzen [9].

Horregatik, estatistika irakasteko, ezinbestekoa dugu hezkuntzaren lehenengo urteetatik eguneroko bizitzako esperientzietan oinarritzea, adibidez egunkarietan eta beste txostenetan agertzen diren datuen azterketan. Baina, zer agertzen ote da Euskal Autonomia Erkidegoan Oinarrizko Hezkuntzaren curriculumean estatistikari buruz?

\section{EUSKAL AUTONOMIA ERKIDEGOAN OINARRIZKO HEZKUNTZAREN CURRICULUMA}

Hasteko, Lehen hezkuntzako curriculuma irakurtzerakoan [10], estatistika matematika ikasgaiaren barruan agertzen da, matematikarako gaitasuna oinarrizko gaitasuna dugularik,

«... zenbakiak, horien eragiketak, matematika-sinboloak eta matematikako adierazpen eta arrazoitze moduak erabiltzeko eta lotzeko trebetasuna da, bai informazioa sortzeko eta interpretatzeko, bai errealitateko alderdi kuantitatibo eta espazialei buruzko jakintza handitzeko, bai eguneroko bizitzako eta laneko arazoak konpontzeko [....]» (BOPV97/2010, 3. Eranskina, 9 or).

Beste jakintza arloetan eta eguneroko bizitzako egoeretan, haien matematika-jakintasuna aplikatzen badute naturaltasunez eta egoera ezberdinetan, esango dugu ikasleek matematikarako gaitasuna eskuratu dutela.

Euskal Autonomia Erkidegoan Oinarrizko Hezkuntzaren curriculuma aztertzerakoan [10], Lehen Hezkuntzako 4. eduki multzoa «Informazioa tratatu, zoria eta probabilitatea» izendatzen da. Hiru ziklotan zehar estatistikari buruzko oinarrizko kontzeptuak landu behar dira. Besteak bete, kritikoki aztertu nahi da grafiko estatistikoen bidez emandako informazioak duen garrantzia zein den.

Hau lortzeko, grafikoak eta taulak lantzen dira eta datuak biltzeari dagokion garrantzia adierazten da. Zehazki, lehenengo ikasturtetik eta progresiboki, oinarrizko inkestak nola sortu ikasten da; behaketa eta neurketa teknikak erabilita, nola egin datu horien guztien erregistroa; eta nola ez, estatistika-grafikoak lantzen dira: barra-diagramak, piktogramak, maiztasun-poligonoak, eta sektore-diagramak. Oinarrizko kontzeptuen artean, batez besteko aritmetikoa, moda, mediana eta heina ikusten dira. Hauek eguneroko egoeretan aplikatu eta inguruan dauden objektuei, fenomenoei, eta gertaerei buruzko grafiko errazak ere eratzen dira. 
Bukatzeko, EAEko ebaluaziorako irizpideetan ondokoak aurki ditzakegu besteak beste: eguneroko bizitzako gertaerei eta objektuei buruzko datuak biltzea (teknika errazak erabilita), datu horiek ordenatzea (sailkapenirizpidea kontuan hartuta), eta emaitzak taula edo grafiko batean adieraztea. Problemak ondo formulatu eta ebatsi behar dira, sarrera bikoitzeko koadroetan eta grafikoetan adierazitako zenbakizko testuak irakurri eta interpretatuz.

\section{OHIKO AKATSAK: ADIBIDE BAT GURE INGURUAN}

Aurrekoan azaldu duguna kontuan hartuz, garrantzi handia eman behar zaio irakasleen prestakuntzari. Lehen Hezkuntzako graduko ikasleek dituzten aurrezagupenak eta iritziak aztertzen aritu gara.

Atal honetan, hainbat akats mota aztertuko ditugu:

Behin, Euskal Curriculuma aztertuta, Anasagastik eta Bercianok ikertu zuten zer neurritan zeukaten kontrolpean Lehen Hezkuntzako graduko ikasleek etorkizunean irakatsi beharko luketen gaia. Horretarako, hiru bloketan prestatutako testa erabili zuten:

a) zer ezagupen estatistiko mota zeukaten neurtzeko asmoz hainbat item proposatu zituzten. Haietako batzuk Garfielden testetik [6], Castellanosen tesitik [11], baita PISA probatik [12] ere aterata zeuden. Item horien artean batez bestekoa, moda, mediana, sakabanatzea eta grafikoen esanahia neurtzen dituztenak aukeratu ziren;

b) eskolako curriculumean estatistikari buruz zer zekiten baloratzeko bi item diseinatu ziren, eta;

c) estatistikari ematen dioten balioa egiaztatzeko, beste bi item proposatu zituzten.

Ikerketa honetan Bilboko Irakasleen Unibertsitate Eskolako Lehen Hezkuntzako Graduko lehenengo mailan zeuden 144 ikaslek parte hartu zuten; haien adinak 18 eta 35 urte artekoak ziren. Horietako 38 gizonak ziren eta 106 emakumeak.

Lehenengo blokean biltzen den ezagupen estatistiko horri dagokionez, azpimarratu behar da ikasleek oinarrizko kontzeptuak (moda, batez bestekoa, mediana) ezagutzen dituztela, baina askotan ez dituztela esanahiak guztiz ondo ulertzen. Gainera sakabanatze neurriei buruz ari direnean akats ugari egiten dituzte. Banaketa asimetrikoei dagokienez, nabarmenak dira batez bestekoa, moda eta medianaren posizio erlatiboak ulertzeko dituzten eragozpenak [13]. Lehenengo bost itemetan lortutako emaitzak ditugu hauen guztien adibide. 
Lehenengo itemean desbideratze bera baina batez besteko ezberdina duten bi multzoen arteko konparaketa egitea eskatzen zitzaien, ea sakabanatzearen kontzeptua ulertzen zuten. Bi multzoen sakabanatzeen berri eskatuta ikasleen erdiak baino gehiagok (\% 50.7k) sakabanatze berdina dutela erantzuten dute, desbideratzea eta sakabanaketa zuzenki lotuz, eta batez bestekoen balioak kontuan izan gabe. Ikasleen \% 11.8k baizik ez du erantzun zuzena aukeratzen.

Bigarren itemean, ikasleei batez bestekoaren kalkulua eta bere kalkulurako ponderazioen aplikazio egokia eskatzen zitzaien, maiztasun taula sinple baten datuak hartuta. Nahiz eta kasu honetan gehiengoak (\% 69.4k) erantzun eta adierazpen zuzena eman, ikasleen \% 19.4k erantzun okerra ematen du, batez besteko kalkulua egiteko orduan ponderazio edo maiztasunak ez dituztelako kontuan hartzen. Akats hau kezkagarria da oso.

Hirugarren itemean, aztertu nahi zen grafiko baten irakurketa egokiro egiten zuten. Grafika honetan, kontuan hartu behar zituzten ordenatuen edo Y ardatzaren balioak, ez zirelako hasten 0tik, 400 baliotik baizik. Kasu honetan, ikasleen gehiengoak irakurketa zuzena egin zuten, baina \% 30.6k ez du grafika sinple hau behar den moduan ulertu eta ondorioz, datuen interpretazio okerra egin zuten.

Laugarren itemean, batez bestekoa, moda eta mediana kontzeptuei buruz eta era berean banaketa asimetrikoetan har ditzaketen kokapen erlatiboei buruz galdetzen zen. Gainera, ikusi nahi zen ea bazekiten batez bestekoaren kalkulu algoritmoa alderantzizko eran aplikatzen. Kasu honetan, $\%$ 58.3k baizik ez du ondo egiten. Beste erantzun okerretatik ondoriozta daiteke ikasleek ez dituztela batez bestekoa, moda eta medianaren kokapen erlatiboak ondo erabiltzen tartean banaketa asimetrikoak daudenean; horretaz gain, ez dute balio atipikoen eragina kontuan hartzen.

Bosgarren itemean, aztertu nahi zen neurketa zehatz batean balio ezberdinak lortzerakoan, batez bestekoa estimaziozko balio fidagarriena moduan aukeratzen ote zuten. Gainera, balio atipikoek bere kalkuluan duten eragina antzeman behar zuten. Kasu honetan, gehienek (\% 94.5ek) batez bestekoa estimaziozko balio onena balitz bezala aukeratzen dute. Kasu honetan balio atipikoa ez baztertzea izan da akats nagusia.

Laburbilduz, emaitzetatik ondoriozta dezakegu ikasleek oinarrizko edukiak ezagutzen dituztela orokorrean. Adierazpen grafikoak irakurtzera ohituta daude, baina hala ere, batzuetan interpretazioa egiterakoan okertu egiten dira. Nabarmena da batez bestekoa kalkulatzeko erraztasuna baina interpretatzerakoan galdu egiten dira, esate baterako-arruntak ez diren balioak agertzen direnean edo alderantzizko algoritmoa kalkulatu behar dutenean.

Bigarren blokean Curriculumari buruzko ezagupenak baloratu behar ziren eta, ondorioztatu zen portzentaje handian, ikasleek ez zutela ezberdin- 
tzen estatistika beste arlo matematikoetatik, eta ez zekitela zeintzuk ziren Lehen Hezkuntzako ikasleen estatistikari buruzko ezagupena ebaluatzeko irizpide egokiak [14].

Hirugarren bloketik, ondoriozta daiteke ia erdiari estatistika baliagarria iruditzen zaiola, bai arlo zientifikoan bai bizitzako egoeretan; beste erdiak ordea, ez du hain interesagarria ikusten estatistika. Zehazkiago, lehenengo galderan aztertu zen ea beharrezkoa ikusten zuten estatistika Unibertsitateko hainbat gradutan. Hartutako gradu guztiek estatistika zeukaten haien programan, baina aztertutako ikasleek ez zuten hain argi ikusten estatistika beharrezkoa zenik (10 graduak emanda, hurrengo grafikoan ikus daiteke zenbat aukeratu zuen ikasle bakoitzak).

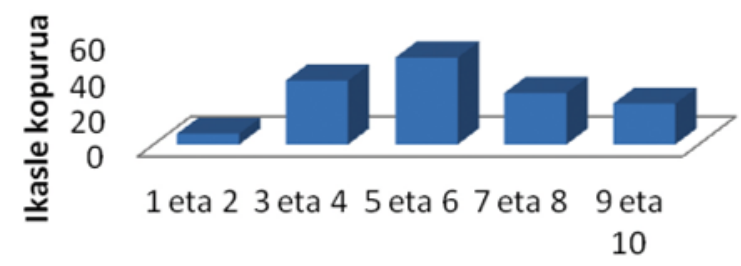

Aukeratutako gradu kopurua

1. irudia. Estatistika gradu ikasketetan.

Bigarren galderan, aztertu zen ea estatistika baliagarria izan zitekeen egoera arruntetan; hain zuzen ere, azaldu zitzaizkien bost egoeretan, estatistika benetan lagungarria gertatuko litzateke.

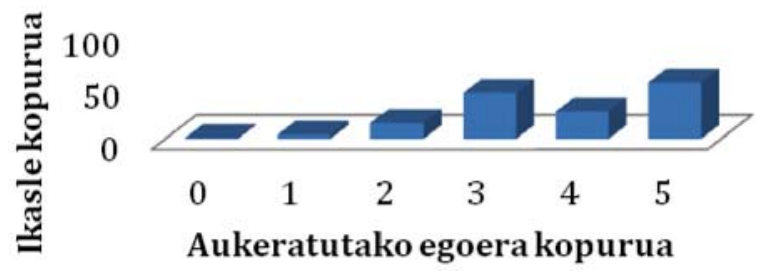

2. irudia. Estatistika hainbat lanbidetan.

Berriro ondorioztatzen zen $\% 55.6 \mathrm{k}$ interesgarria eta baliagarria ikusten zuela, baina beste $\% 44.4 \mathrm{k}$ aldiz, ez zuela uste estatistika hain baliagarria zenik egoera arruntetan. 
Lehen esan dugun bezala, datu hauetan ikus daiteke gure ikasleek, nahiz eta lehen hezkuntzatik batxilergora estatistika ikasi, ez dakitela zer eduki ez eta zer ebaluatzeko irizpide daukan estatistikako blokeak. Gainera, portzentaje handi batean ez dute ikusten estatistika baliagarria dela ez unibertsitateko graduak ikasteko ezta egoera arruntetarako. Horregatik, ezinbestekoa dugu zertarako balio duen zehatz-mehatz azaltzea ikasleei.

\section{ONDORIOA}

Orain arte azaldu duguna azalduta, argi dago irakaskuntza klasikoak ez diola estatistikari lagundu, hau da, nahiz eta kontzeptuak azaldu eta prozesuak aztertu, hainbatek ez dakite grafiko batetik ezer ondorioztatzen ezta kontzeptu desberdinak elkarrekin uztartzen. Lehenengo zatian, azaldu dugun bezala, honek eragin handia dauka gure eguneroko bizitzan, eta beraz, metodologia-aldaketa proposatu beharko litzateke estatistika-hezkuntzan egoera aldatzeko.

Cockroft txostena aztertzen bada [15], garbi ikus daiteke matematikaren irakaskuntzak, eta ondorioz, estatistika irakaskuntzak, hurrengo oinarrizko euskarriak izan beharko lituzkeela: irakaslearen azalpenak eta irakasle eta ikasleen arteko eztabaidak. Horretarako, eskatutako lanak erabilgarriak eta egokiak izan beharko lirateke; era berean, eguneroko bizitzarako aplikazioetan oinarritutako problemak landu beharko lirateke; bukatzeko, ikerketako lanak ere.

Azken hauek kontuan hartuta, argi dago hezkuntzaren metodologia aldatu behar dela, eta hemen Problematan Oinarritutako Irakaskuntza (POI) proposatzen dugu. Berciano eta Gutierrezek diote POI metodologia ikasgeletan/eskoletan erabiltzeak eragin positiboa daukala ikasleengan, hain zuzen ere, guztiz aldatu zirela haien hezkuntza-esperimentuan probatu zuten ikasleen matematikari buruzko iritzia eta partaidetza; gainera motibazioa pizteko oso komenigarria zela ikusi zen [16].

Bukatzeko, estatistika ikasteko errealitatean oinarritutako gaiak lantzea proposatzen dugu. Ikasleak, interesgarriak diren datuen bilketan ohitu behar ditugu. Datu-bilketaz baliatuko gara aldagai estatistikoak lantzeko ere, aldagai kualitatiboak eta kuantitatiboak desberdinduz eta behar den moduan baloratuz. Honek guztiak etorkizuneko irakasleari aukera emango dio benetako problemak ebazteko tresna praktiko eta zuzena eskuratzeko. Hona adibide bat:

1. Arazoaren planteamendua. Bere inguruko arazo bat hautatu behar dute ikasleek. Ikertu nahi duten definizioari erreparatu behar diote bereziki zentratu behar dira eta fenomenoa behatzeko galdetegia sortu behar dute. 
2. Datu-bilketaren metodologia bat aukeratu behar dute. Laginak ikasleen talde desberdinekin egingo ditugu.

3. Datuen analisia. Pauso hau izango da garrantzitsuena, datuen antolaketa eta aztertzeko beharrezkoak diren tresnak ondo erabiltzea hain zuzen.

4. Ondorioak. Datuak aztertuta, emaitzen laburpena egitera abiatu beharko dira.

Gure ustez, prozesu honetan landutako gaitasunak laguntza emango du irakasle-jardunean estatistikari buruzko kontzeptuak ulertzen eta Lehen Hezkuntzarako jarduera egokiak proposatzen.

\section{BIBLIOGRAFIA}

[1] KI-MOON B. 2010. 2010.eko urriaren 20ko Nazio Batuak erakundearen izenean, estatiska egunaren mezua. http://www.un.org/en/events/statisticsday/sg message.shtml

[2] OECD. 2003. The PISA 2003 Assessment Framework. Mathematics, Reading, Science and Problem Solving Knowledge and Skills. París: OCDE

[3] OECD. 2004. Marcos teóricos de PISA 2003: la medida de los conocimientos y destrezas en matemáticas, lectura, ciencias y resolución de problemas. Madrid: Ministerio de Educación y Ciencia, Instituto Nacional de Evaluación y Calidad del Sistema Educativo.

[4] MOORE D. S. 1990. «Uncertainty». En L. A. STEEN (Eds.). On the shoulders of giants. New approaches to numeracy, 183-217. Washington, D. C.: National Academy Press.

[5] SHAUGHNESSY J. M., GARFIELD J. eta GEER B. 1996. «Data handling». In A. J. BISHOP, K. CLEMENTS, C. KEITEL, J. KILPATRICK eta C. LABORDE (Eds.). International handbook of Mathematics Education, $\mathbf{1}$, 205-237. Dordrecht. Netherlands: Kluwer.

[6] GARFIELD J. 2003. «Assessing statistical Reasoning». Statistics Education Research Journal, 2, 22-38.

[7] LEAVY A. 2010. «Teaching statistics at the primary level: identifying obstacles and challenges in teacher preparation from looking at teaching». ICOTS8.

[8] ESTRADA A. 2004. «Evaluación del conocimiento estadístico en la formación inicial del profesorado». Tesis Doctoral. Universidad de Lleida.

[9] ARTEAGA P., BATANERO C. eta RUIZ B. 2009. «Comparación de distribuciones por futuros profesores». Investigación en Educación Matemática XIII (SEIEM), 129-138.

[10] BOPV97/2010. 2010. Euskal Autonomia Erkidegoan Oinarrizko Hezkuntzaren curriculuma. http://www.euskadi.net/bopv2/datos/2010/04/1002109a.pdf

[11] CASTELLANOS R. 2011. «Interactividad y atención a la diversidad en el Aprendizaje de la Estadística». Tesis Doctoral. Universidad de La Rioja. 
[12] OECD. 2009. Informe PISA 2009: ¿La asistencia a educación infantil se traduce en mejores resultados en el aprendizaje escolar? Madrid: Ministerio de Educación y Ciencia, Instituto Nacional de Evaluación y Calidad del Sistema Educativo.

[13] ANASAGASTI J. eta BERCIANO A. 2012. «Prueba exploratoria sobre competencias de futuros maestros de primaria: conocimiento de conceptos básicos de estadística». En A. ESTEPA CASTRO, Á. CONTRERAS DE LA FUENTE, J. DEULOFEU PIQUET, M. C. PENALVA MARTÍNEZ, F. J. GARCÍA GARCÍA, L. ORDÓÑEZ CAÑADA (Eds.). Investigación en Educación Matemática XVI (SEIEM), 113-122, Baeza: SEIEM.

[14] ANASAGASTI J. eta BERCIANO A. 2013. «Prueba exploratoria sobre competencias de futuros maestros de Primaria: conocimiento del bloque relativo al tratamiento de la información, azar y probabilidad, en el currículo escolar de Matemáticas». Primeras Jornadas Virtuales en Didáctica de la Estadística, Probabilidad y Combinatoria. 5 y 6 de abril de 2013.

[15] COCKROFT W. H. 1985. Las matemáticas sí cuentan. Informe Cockroft. Madrid: Ministerio de Educación y Ciencia.

[16] GUTIÉRREZ G. eta BERCIANO A. 2012. «Un experimento de enseñanza sobre la influencia del ABP en la competencia matemática con futuras maestras de educación infantil». En A. ESTEPA CASTRO, Á. CONTRERAS DE LA FUENTE, J. DEULOFEU PIQUET, M. C. PENALVA MARTÍNEZ, F. J. GARCÍA GARCÍA, L. ORDÓÑEZ CAÑADA (Eds.). Investigación en Educación Matemática XVI (SEIEM), 353-362, Baeza: SEIEM. 